\title{
X-ray absorption spectroscopy study of the chemistry of «invisible» Au in arsenian pyrites
}

\author{
Olga Filimonova, ${ }^{1,}$, Alexander Trigub ${ }^{2}$, Maximilian Nickolsky $^{1}$, Elena Kovalchuk $^{1}$, Vera \\ Abramova $^{1}$, Mauro Rovezzi ${ }^{3}$, Elena Belogub ${ }^{4}$, Ilya Vikentyev ${ }^{1}$, and Boris Tagirov ${ }^{1}$ \\ ${ }^{1}$ Institute of Geology of Ore Deposits (IGEM RAS), 35, Staromonetny per., 119017 Moscow, Russia \\ ${ }^{2} \mathrm{NRC}$ "Kurchatov Institute", Moscow, Russia \\ ${ }^{3}$ ESRF, 71, avenue des Martyrs CS 40220, 38043 Grenoble, France \\ ${ }^{4}$ Institute of Mineralogy, Urals Branch of RAS, Chelyabinsk District, 456317 Miass, Russia
}

\begin{abstract}
Arsenian pyrite is an abundant mineral occurring in many geological settings at the Earth's surface, including hydrothermal ore deposits which are the main source of Au. So-called "invisible" (or refractory) form of $\mathrm{Au}$ is present in pyrites in all types of these deposits, and its concentration is often directly correlated with As content. Here we report results of the investigation of the local atomic structure of $\mathrm{Au}$ in natural $\left(\mathrm{Cu}\right.$-Au-porphyry) and synthetic $\left(450{ }^{\circ} \mathrm{C} / 1 \mathrm{kbar}, 300{ }^{\circ} \mathrm{C} / \mathrm{Psat}\right) \mathrm{As}-$ free and As-bearing pyrites by means of $\mathrm{X}$-ray absorption spectroscopy (XAS). In addition, the state of As was determined in pyrite samples from Carlin-type deposit. XANES/EXAFS measurements, compiled with previously published data, revealed the chemical state (valence state, local atomic environment) of $\mathrm{Au}$ and $\mathrm{As}$ in arsenian pyrites. Au is present in the solid solution state $\left(\mathrm{Au}^{1+}\right.$ in the Fe position, octahedrally coordinated by $\mathrm{S}$ atoms), as well as in $\mathrm{Au}^{1+}{ }_{2} \mathrm{~S}$ clusters ( $\mathrm{Au}^{1+}$ linearly coordinated by $2 \mathrm{~S}$ atoms). The admixture of As has no effect on the Au valence state and $\mathrm{Au}-$ $\mathrm{S}$ interatomic distance, except one synthetic sample containing a minor amount of FeAsS. Arsenic mostly incorporates into the anion site in pyrite lattice $\left(\mathrm{S}^{1-} \leftrightarrow \mathrm{As}^{1-}\right)$. Our data demonstrate that pyrites of hydrothermal origin can host up to $\sim 300 \mathrm{ppm}$ of structurally bound "invisible" $\mathrm{Au}$ independently of As content.
\end{abstract}

\section{Introduction}

Arsenian pyrite is a typical host mineral of Au in many types of deposits, including $\mathrm{Cu}-$ Au-porphyry and Carlin-type deposits. Numerous studies showed a strong positive correlation between $\mathrm{Au}$ and $\mathrm{As}$ in arsenian pyrite ([1], and references therein). Previous Xray absorption near edge structure (XANES) measurements of Au-As-bearing pyrite detected $\mathrm{Au}^{0}$, or chemically bound $\mathrm{Au}^{1+}$, or both forms [2]. The XANES/EXAFS (Extended $\mathrm{X}$-ray absorption fine structure) spectroscopy was used earlier to determine the chemical state of As, which isomorphically substitutes for $\mathrm{S}$ in anion site $\mathrm{Fe}\left(\mathrm{S}, \mathrm{As}^{1-}\right)_{2}$ [3] and/or for $\mathrm{Fe}$ in cation site $\left(\mathrm{Fe}, \mathrm{As}^{2+/ 3+}\right) \mathrm{S}_{2}$ [4]. The aim of our study is to characterize the chemical

\footnotetext{
*Corresponding author: o.filimonova@igem.ru
} 
state of both «invisible» Au and As in synthetic and natural As-free and As-bearing pyrites by means of X-ray absorption spectroscopy (XANES/EXAFS).

\section{Spectroscopic measurements and data treatment}

The Au $L_{3}$-edge and As $K$-edge X-ray absorption spectra were recorded at BM16 FAMEUHD beamline of ESRF (Grenoble, France) and STM beamline of KSRS (Moscow, Russia, only As $K$-edge spectra). The High Energy Resolution Fluorescence Detection mode (HERFD) was employed to record $\mathrm{Au}$ spectra. Simultaneously the Total Fluorescence Yield (TFY) As spectra were acquired. XAS data reduction was performed using IFEFFIT package [5].

\section{Results}

\subsection{Composition of Au-(As)-bearing pyrites}

Natural pyrite from Samolazovskoe $\mathrm{Cu}$-Au-porphyry deposit, Yakutia, and Vorontsovka Carlin-type deposit, Urals, Russia, and pyrites synthetized by hydrothermal method at 450 ${ }^{\circ} \mathrm{C} / 1 \mathrm{kbar}$ (No. 8, 10, 16, 6/14) and $300{ }^{\circ} \mathrm{C} /$ Psat (No. 17/1, 17/2, 5/2) were examined using XRD, SEM, EPMA, and (LA)-ICP-MS. The XRD pattern of all samples corresponded to pure pyrite PDF\#42-1340 (within 5 vol\% of misfit fraction). SEM/EDS analysis revealed a small amount of arsenopyrite (No. 5/2), or arsenopyrite and löllingite (No. 17/2) admixtures, and As-S amorphous phases (No. 16), the other samples contained only pure pyrite. The (LA)-ICP-MS analyses yielded the concentration of "invisible" $\mathrm{Au}$ in pyrites from 75 to $360 \mathrm{ppm}$, As content varied between $<0.2 \mathrm{ppm}$ (detection limit) in As-free samples (No. 8, 6/14, 17/1) and $>6 \mathrm{wt} \%$ in As-bearing pyrites. In accordance with (LA)ICP-MS analyses there was no distinct correlation between $\mathrm{Au}$ and As contents. Despite the fact that both $\mathrm{Au}$ and As contents varied considerably from one sample to the other and within a single aggregate, smooth character of LA-ICP-MS time-resolved spectra of single spot analyses and line scans indicated the absence of micronuggets of Au-bearing phases.

\subsection{XANES spectroscopy}

Figure 1 (left) shows Au $L_{3}$-edge XANES spectra of the Au-(As)-bearing pyrites together with the spectra of standards. We observed a significant rightward energy shift of the edge jump (e.j.) of pyrite samples in comparison with the metallic Au. At the same time, the e.j. positions of $\mathrm{Au}$ in As-bearing and As-free pyrites, $\mathrm{Au}_{2} \mathrm{~S}$, and $\mathrm{Au}$ in FeAsS fell within the uncertainty of the measured energies. In general, the low WL intensity of samples and references suggests that the formal oxidation state of $\mathrm{Au}$ is +1 . Independently of the amount of the admixtures and pyrite type (natural/synthetic), samples can be divided into two groups based on their WL intensity: (i) the high WL intensity group (No. 8522, 17/1 - Au mostly presents in the solid solution), and (ii) the low WL intensity group (Au is present in the solid solution state and as $\mathrm{Au}_{2} \mathrm{~S}$ clusters). Significant decrease of the WL intensity of sample No. 17/2, probably, takes place due to incorporation of Au into the cation site of both arsenian pyrite and arsenopyrite/ löllingite, and because of the presence of $\mathrm{Au}_{2} \mathrm{~S}$. 
Figure 1 (right) demonstrates As $K$-edge XANES spectra of Au-As-bearing pyrites and reference compounds. Positions of e.j. and WL of pyrites from Vorontsovka deposit ( $\sim 11865.8$ and $11867.8 \mathrm{eV}$, correspondingly) are between those of $\mathrm{As}^{3+}{ }_{2} \mathrm{~S}_{3}$ and $\mathrm{FeAs}{ }^{1-} \mathrm{S}$. The WL position of sample No. 8522 (Samolazovskoe deposit), and synthetic samples 10, 16 , and $5 / 2$ is close to löllingite $\mathrm{FeAs}^{1-}{ }_{2}(\sim 11869.0 \mathrm{eV})$. Thus we suggest that most As in these pyrites exists in the formal oxidation state $-1\left(\mathrm{~S}^{1-} \leftrightarrow \mathrm{As}^{1-}\right)$. XANES spectrum of sample No. 16 is slightly shifted to lower energies towards $\mathrm{As}_{2} \mathrm{~S}_{3}$, which may be explained by the presence of As-S amorphous quench phase. In sample No. 5/2, in addition to As ${ }^{1-}$ WL $\left(\sim 11869.7 \mathrm{eV}\right.$, which is equal to $\left.\mathrm{FeAs}^{1-}{ }_{2}\right)$, a second feature at $11874.6 \mathrm{eV}$ is attributed to $\mathrm{As}^{5+}$. In sample No. 17/2 the second feature is more intense, suggesting the higher $\mathrm{As}^{5+}$ concentration. Almost all samples contain an admixture of As-O phase (except pyrites from Vorontsovka deposit).
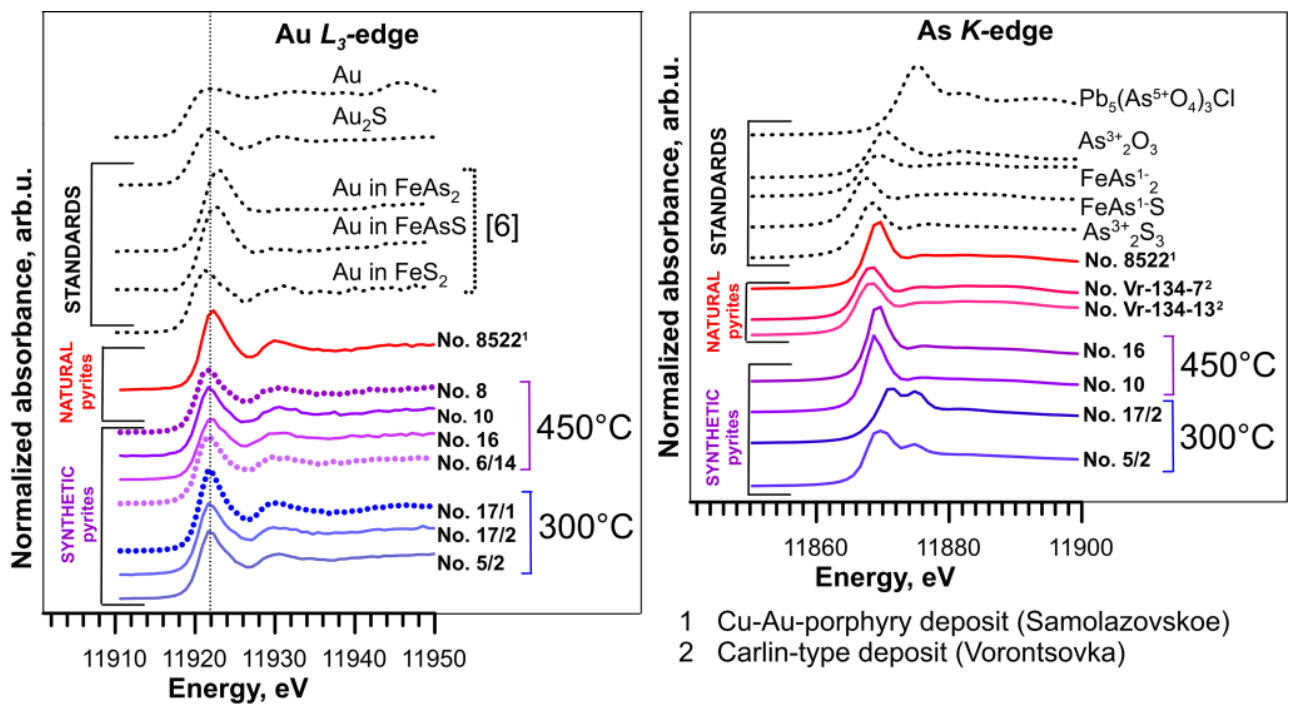

Fig. 1. Au $L_{3}$-edge (left) and As $K$-edge (right) XANES spectra of As-bearing (solid lines) and Asfree pyrites (dotted lines), and model substances (black dashed lines). Vertical line indicates position of the most intense spectral feature (WL) of Au-bearing pyrite samples (color online).

\subsection{EXAFS spectroscopy}

The EXAFS spectra of Au $L_{3}$-edge and As $K$-edge are shown in Fig. 2. For natural arsenian pyrite No. 8522 (Fig. $2 a$ ) the best fit of the experimental Au $L_{3}$-edge spectrum is achieved when Au substitutes for Fe $\left(N_{S} \sim 6, R_{\mathrm{Au}-\mathrm{S}} \sim 2.40 \AA\right)$. Similar parameters of the local atomic environment of $\mathrm{Au}$ were observed in As-free pyrite No. $17 / 1$ synthesized at $300{ }^{\circ} \mathrm{C}$. In these samples $R_{\mathrm{Au}-\mathrm{S}}$ and $R_{\mathrm{Au}-\mathrm{Fe}}$ of distant coordination shells correspond to the pure pyrite structure. Therefore, the admixture of As has no effect on the local atomic environment of $\mathrm{Au}$ in pyrite. In pyrites synthesized at $450{ }^{\circ} \mathrm{C}$ (Fig. $2 c, d$ ) $\mathrm{Au}$ is also surrounded by $\mathrm{S}$ atoms, the interatomic distances $R_{\mathrm{Au}-\mathrm{S}}$ vary between $2.32-2.45 \AA$ and are directly correlated with the number of the nearest $\mathrm{S}$ atoms $\left(N_{S}=3-7\right)$. The direct correlation $R_{\mathrm{Au}-\mathrm{S}}$ vs $N_{S}$ can be explained by the formation of $\mathrm{Au}_{2} \mathrm{~S}$ (Fig. $2 f$, for pure $\mathrm{Au}_{2} \mathrm{~S}_{\text {(cr) }} N_{S}=2$ and $R_{\mathrm{Au}-\mathrm{S}}$ $=2.30 \AA$ ). In sample No. $17 / 2$ (synthesis at $300{ }^{\circ} \mathrm{C}$ ) $\mathrm{Au}$ in the $1^{\text {st }}$ coordination shell is surrounded by both $\mathrm{S}\left(N_{S} \sim 3, R_{\mathrm{Au}-\mathrm{S}} \sim 2.37 \AA\right)$ and $\mathrm{As}\left(N_{A s} \sim 3, R_{\mathrm{Au}-\mathrm{As}} \sim 2.55 \AA\right)$ atoms. The distant coordination shells of $\mathrm{Au}$ in this sample are best described by the combination of pure pyrite and arsenopyrite structures. This model is consistent with the presence of at 
least two forms of $\mathrm{Au}$, which is located in the cationic positions in both pyrite and arsenopyrite, and, probably, in $\mathrm{Au}_{2} \mathrm{~S}$ clusters.

\section{Au $L_{3}$-edge}
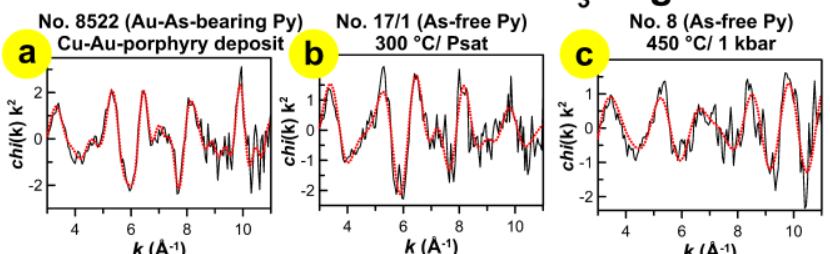

No. 10 (As-bearing Py)
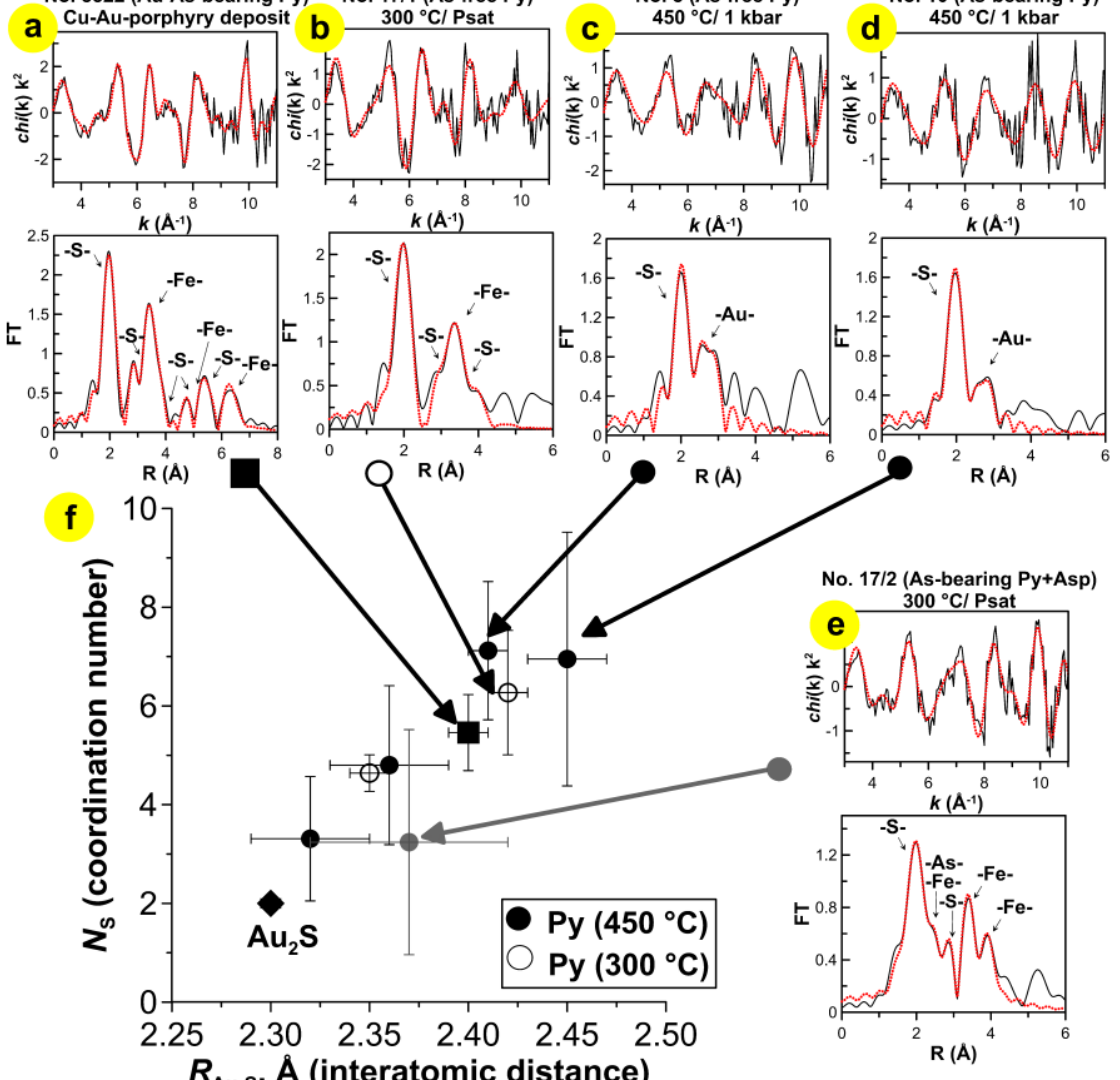

$R_{\text {Au-S }}, \AA$ (interatomic distance)

As K-edge

No. 8522 (Au-As-bearing Py) No. Vr-134-7 (Au-As-bearing Py) No. 17/2 (As-bearing
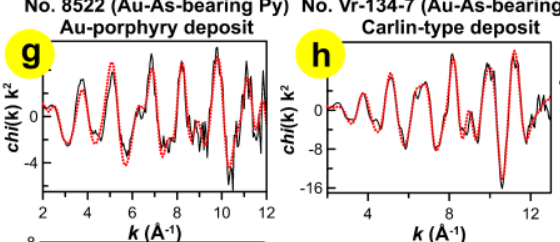
i

No. 10 (As-bearing Py) Py+Asp) $300^{\circ} \mathrm{C} /$ Psat
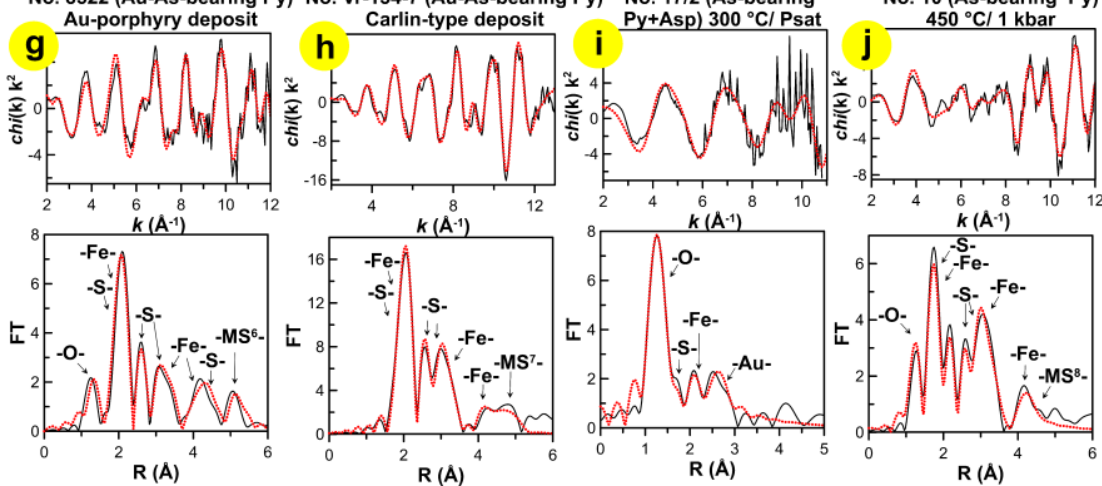

Fig. 2. EXAFS spectra of Au-(As)-bearing natural and synthetic pyrites (Py). Top: $k^{2}$ - and $k^{3}$ weighted background-subtracted Au $L_{3}$-edge spectra $(\boldsymbol{a}-\boldsymbol{e})$, and As $K$-edge EXAFS spectra $(\boldsymbol{g}-\mathbf{j})$, respectively. Bottom: Fourier transforms (FT) of the EXAFS spectra (not corrected for phase shift). Thin black lines - experiment, dotted red lines - fit results. Scattering atoms are indicated near FT peaks. $(\boldsymbol{f})$ : Interatomic distance $\left(R_{A u-S}\right)$ as a function of coordination number $\left(N_{S}\right)$. Samples contain both $(\mathrm{Fe}, \mathrm{Au}) \mathrm{S}_{2}$ and $\mathrm{Au}_{2} \mathrm{~S}$. The presence of $\mathrm{Au}_{2} \mathrm{~S}$ clusters with a short Au-S interatomic distance results in decrease of the $R_{A u-S}$ and $N_{S}$ in the $1^{\text {st }}$ coordination shell (color online). 
Arsenic is coordinated by $\mathrm{O}$ atoms $\left(R_{A s-O} \sim 1.73 \AA\right)$ in almost all arsenian samples (except pyrites from Vorontsovka deposit) due to the small additional fraction of As-O compounds (e.g., $\mathrm{As}^{3+}{ }_{2} \mathrm{O}_{3}$ ). We divided all studied samples into two groups according the $R_{A s-S}$ values: $\sim 2.27 \AA$ (natural pyrites and $5 / 2$ ) and $\sim 2.14 \AA$ (No. 10, 16, 17/2), which is close to the S-S bond length in the structure of pure pyrite. The fitting of the distant coordination shells showed that As replaces mainly $\mathrm{S}^{1-}$ in pyrite structure. We did not observe a contribution of any heavy atom to As $K$-edge EXAFS spectra up to the distant coordination shells with the exception of sample No. 17/2 ( $\left.N_{A u}=1, R_{\mathrm{As}-\mathrm{Au}} \sim 2.56 \AA\right)$ (Fig. 2 i) despite high $\mathrm{Au}$ and As concentrations. In this sample the Au-As, and As-Au interatomic distances are close to that of FeAsS (cf. [6]).

\section{Discussion}

Our data demonstrated the presence of two forms of "invisible" $\mathrm{Au}$ in pyrite: $\mathrm{Au}^{1+}$ in the solid solution state, and $\mathrm{Au}^{1+}{ }_{2} \mathrm{~S}$ clusters. Significant fraction of the latter resulted in the decrease of the Au-S bond length and coordination number observed by means of the EXAFS spectra fitting. Only one sample of As-bearing synthetic pyrite contained Au which was coordinated by both $\mathrm{S}$ and As atoms. SEM/EDS and EPMA analyses of this sample showed the presence of additional $\mathrm{FeAsS}$ and $\mathrm{FeAs}_{2}$ phases, which could contain structurally incorporated $\mathrm{Au}$ [6]. This assumption was in line with the fact that the geometry of the nearest and the distant coordination shells of Au were inherited from both $\mathrm{FeS}_{2}$ and $\mathrm{FeAsS}$. Analyses of As $K$-edge XAS data indicated that the formal oxidation state of As in the structure of pyrite is $-1\left(\mathrm{~S}^{1-} \leftrightarrow \mathrm{As}^{1-}\right)$. In addition, our data revealed the presence of minor admixtures of the oxidized As phase which contain $\mathrm{As}^{5+} / \mathrm{As}^{3+}$. The $\mathrm{O}$ atoms were detected in the $1^{\text {st }}$ coordination shell of the oxidized As. Results of the present study indicated that both As-bearing and As-free pyrites of hydrothermal origin can host economical concentrations of structurally bound «invisible» Au.

Acknowledgements. This study was supported by the Russian Science Foundation grant No. 14-1700693-P.

\section{References}

1. P. Deditius, M. Reich, S. E. Kesler, S. Utsunomiya, S. L. Chryssoulis, J. Walshe, R. C. Ewing, GCA, 140, 644-670 (2014)

2. G. Simon, H. Huang, J. E. Penner-Hahn, S. Kesler, L.-S. Kao., Am. Mineral., 84, 1071-1079 (1999)

3. K. S. Savage, T. N. Tingle, P. A. O’Day, G. A. Waychunas, D. K. Bird, Appl. Geochem., 15, 8 (2000)

4. P. Le Pape, M. Blanchard, J. Brest, J. C. Boulliard, M. Ikogou, L. Stetten, S. Wang, G. Landrot, G. Morin, Environ. Sci. Technol., 51, 1 (2016)

5. B. Ravel, M.Newville, J. Synchrotron Rad., 12, 4 (2005)

6. A. L. Trigub, B. R. Tagirov, K. O. Kvashnina, D. A. Chareev, M. S. Nickolsky, A. A. Shiryaev, N. N. Baranova, E. V. Kovalchuk, A. V. Mokhov, Am. Mineral., 102, 5 (2017) 